\title{
A Summary of NASA Architecture Studies Utilizing Fission Surface Power Technology
}

Beginning with the Exploration Systems Architecture Study in 2005, NASA has conducted various mission architecture studies to evaluate implementation options for the U.S. Space Policy (formerly the Vision for Space Exploration). Several of the studies examined the use of Fission Surface Power (FSP) systems for human missions to the lunar and Martian surface. This paper summarizes the FSP concepts developed under four different NASA-sponsored architecture studies: Lunar Architecture Team, Mars Architecture Team, Lunar Surface Systems/Constellation Architecture team, and International Architecture Working Group-Power Function team. The results include a summary of FSP design characteristics, a compilation of mission-compatible FSP configuration options, and an FSP concept-of-operations that is consistent with the overall mission objectives. 


\section{A Summary of NASA Architecture Studies Utilizing Fission Surface Power Technology}

2010 International Energy Conversion Engineering Conference (IECEC)

By

Lee Mason, NASA Glenn Research Center, and

Dave Poston, Los Alamos National Laboratory

July 26, 2010 


\section{Space Nuclear Power}

- Fission Reactor Systems

- SNAP-10A (launched 1965)

- Soviet Buk and Topaz (over 30 systems launched from 1976-1988)

- SP-100 (cancelled 1992)

- Jupiter Icy Moons Orbiter (cancelled 2005)

- Fission Surface Power (present)

- Radioisotope Power Systems

- 44 Successful U.S. Radioisotope Thermoelectric Generators (RTG) Flown Since 1961

- Some Examples:

» Apollo SNAP-27 (1969-72)

"Viking SNAP-19 (1975)

" Voyager MHW-RTG (1977)

" Galileo GPHS-RTG (1989)

» New Horizons GPHS-RTG (2005)

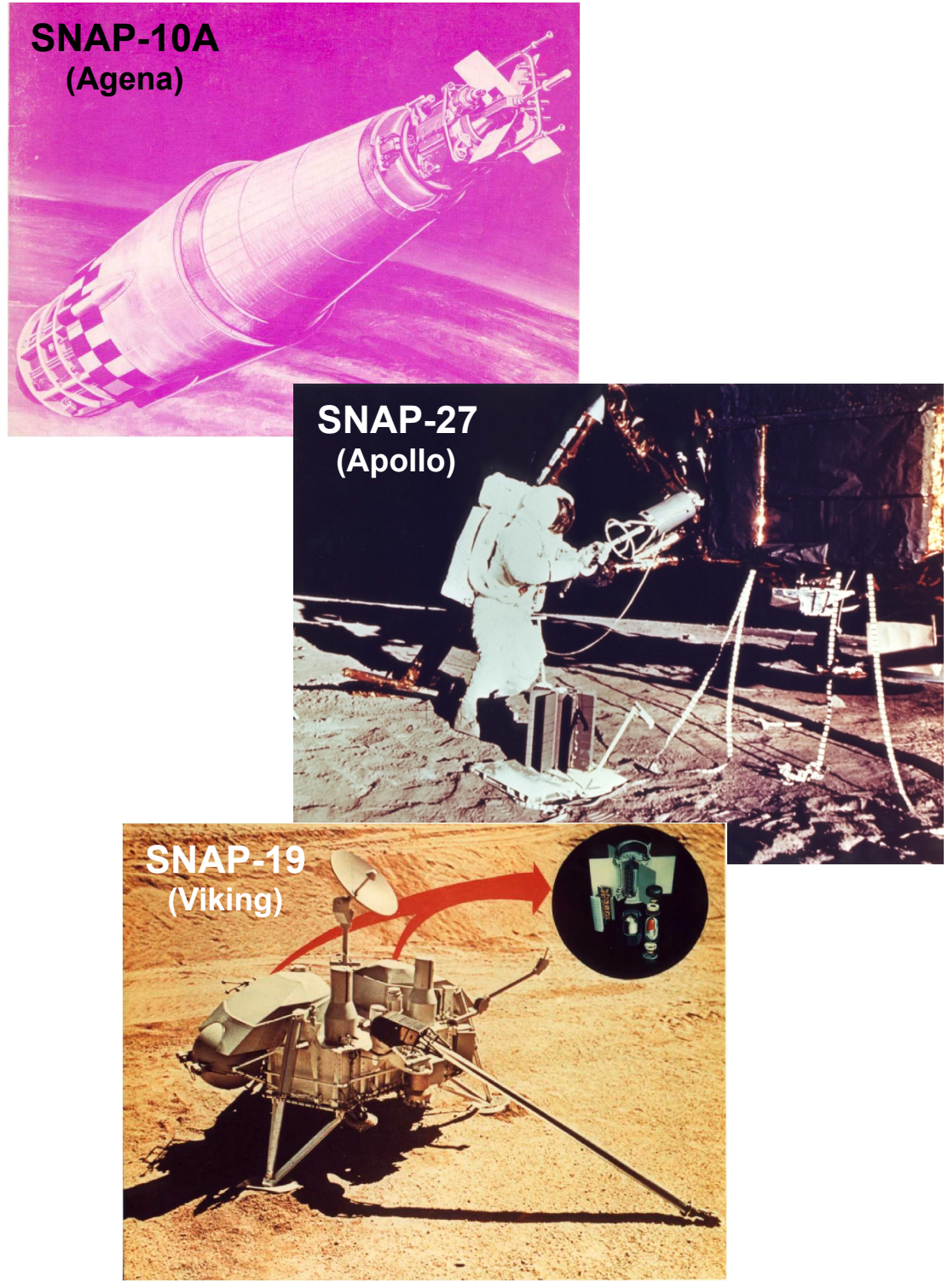




\section{Why Fission Surface Power?}

- Robustness

- Continuous day/night power for expanded surface operations

- Environmentally resilient

- Self-regulating and fault tolerant

- Flexibility

- Suitable for any surface location

- Same technology for moon \& Mars

- Mission-adaptable configurations

- Scalable to higher power levels

- Mission Performance

- Safe during all mission phases

- Mass, volume, and deployed area advantages

- Competitive cost

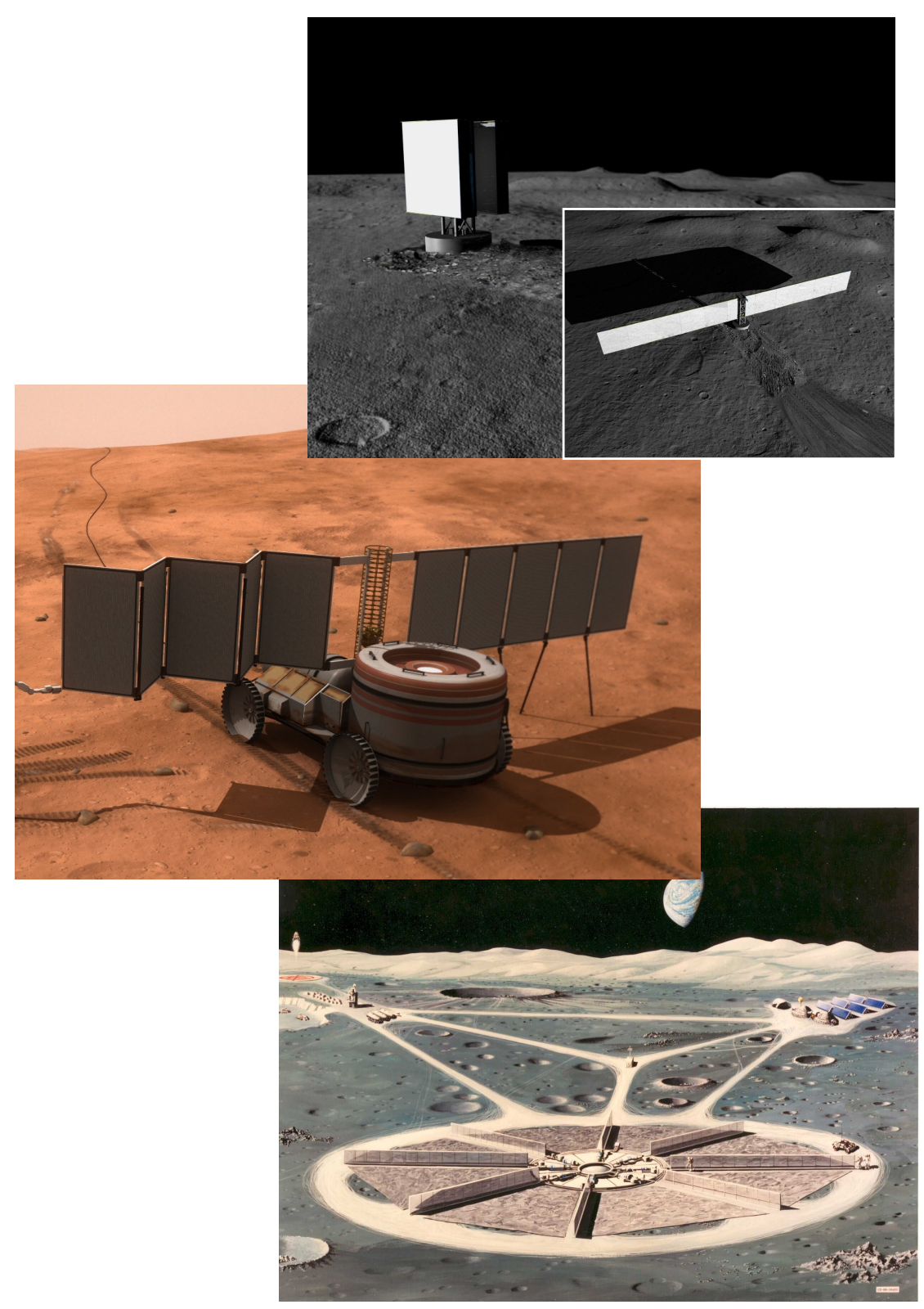




\section{Fission Surface Power Reference Concept}

- Modular 40 kWe system with 8-year design life suitable for (global) lunar and Mars surface applications

- Emplaced configuration with regolith shielding augmentation permits near-outpost siting ( $<5 \mathrm{rem} / \mathrm{yr}$ at $100 \mathrm{~m}$ separation)

- Low temperature, low development risk, liquid-metal (NaK) cooled reactor with $\mathrm{UO}_{2}$ fuel and stainless steel construction

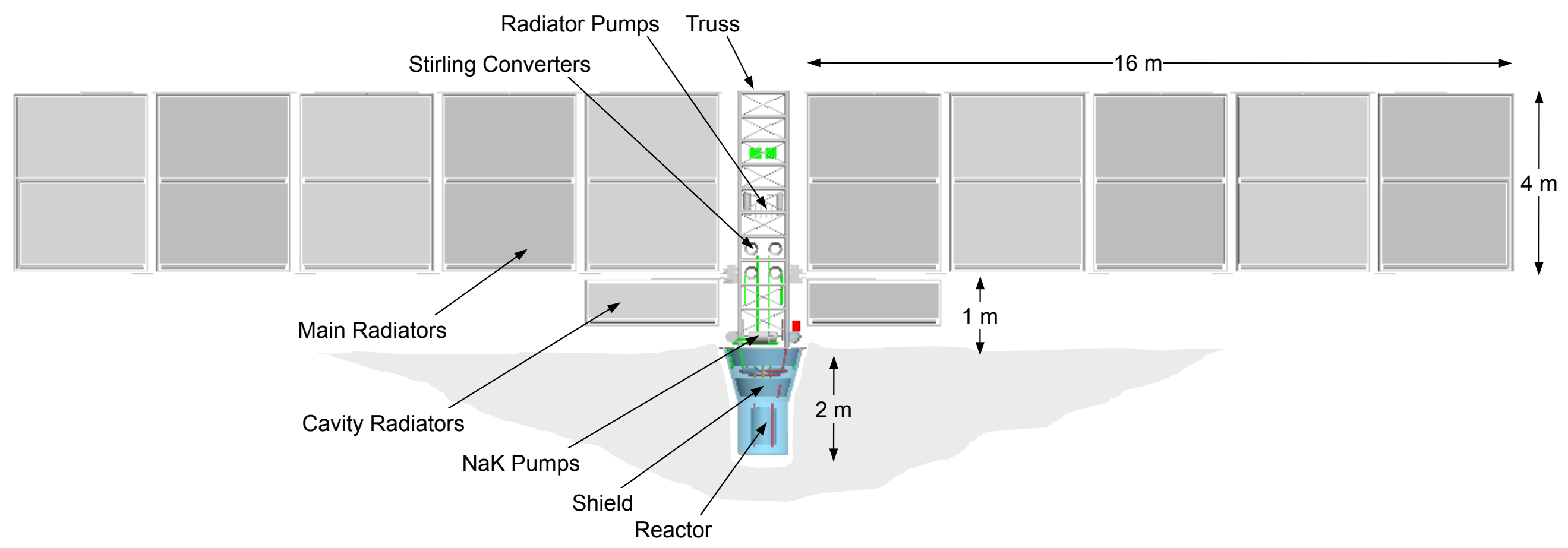




\section{FSP Mass Advantages}
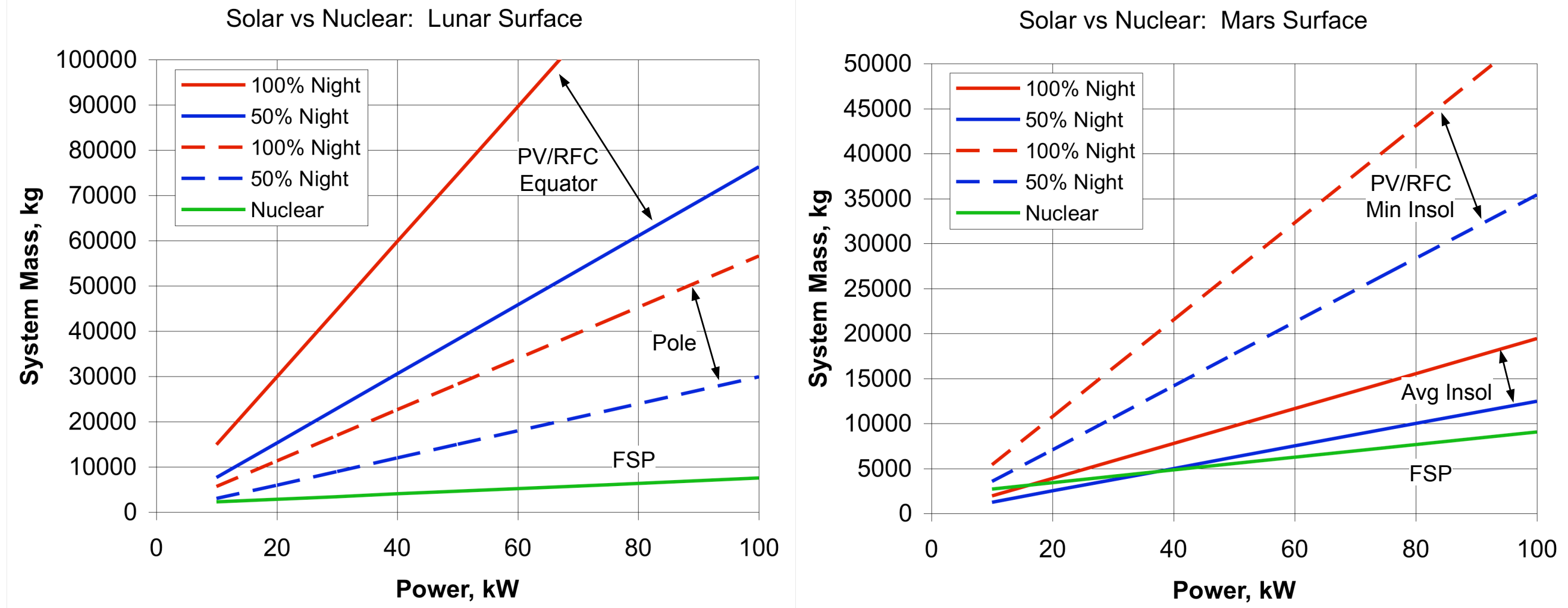

- 25\% Efficient, Sun-Tracking Photovoltaic Arrays with 50\% Round-Trip Efficient Regenerative Fuel Cells providing either $50 \%$ or $100 \%$ Night Power

- Lunar Surface: 1370 W/m2, 354 Hour Night (Equator), 122 Hour Night (Pole)

- Mars Surface: 450 W/m2 (Average), 100 W/m2 (Minimum), 12 Hour Night

- Nuclear Fission Surface Power System with Regolith Shielding; 100\% Day and Night Power 


\section{NASA Architecture Studies}

- Lunar Architecture Team: Option 6

- Based on 40 kWe FSP Reference Concept (buried reactor)

- Detailed Concept-of-Operations generated

- Mars Architecture Team: Design Reference Architecture 5.0

- System pre-deployed with ISRU plant prior to crew departure from Earth

- Alternative wheeled-cart deployment concept developed

- Constellation Architecture Team and Lunar Surface Systems: Scenario 5

- System delivered on $1^{\text {st }}$ cargo lander to support expanded operations

- Alternative lander-integrated system concept developed

- Detailed shielding analyses and mass vs separation distance trade studies

- International Architecture Working Group: Global Point of Departure

- Alternative low power (10 kWe) "movable" concept developed

- Capable of being operated, shut-down, moved to new location, and restarted to support mobility-based architectures 


\section{Lunar Architecture Team - Option 6}

- Shackleton Crater Mission at Lunar South Pole

- Robotic Rover Precursor on First Crew Lander

- Hab and FSP Site Selection

- Crew Ascent Stage Demonstration

- FSP System Delivered on First Cargo Lander

- Central Power Distribution Hub at Outpost

- Remotely-located Reactor Power System (100 m)

- Multi-source Power Grid Connected through Hub

- 3rd Lander Delivers Crew of 4 for 7 Day Mission

- Crew Oversees Hab Setup and FSP Startup

- 1 Cargo + 1 Crew Lander per Year for 10 Years

- ISRU Plant Delivered in Year \#3

- 180 Day Crew Missions begin in Year \#4

- 2nd FSP Unit Delivered in Year \#5

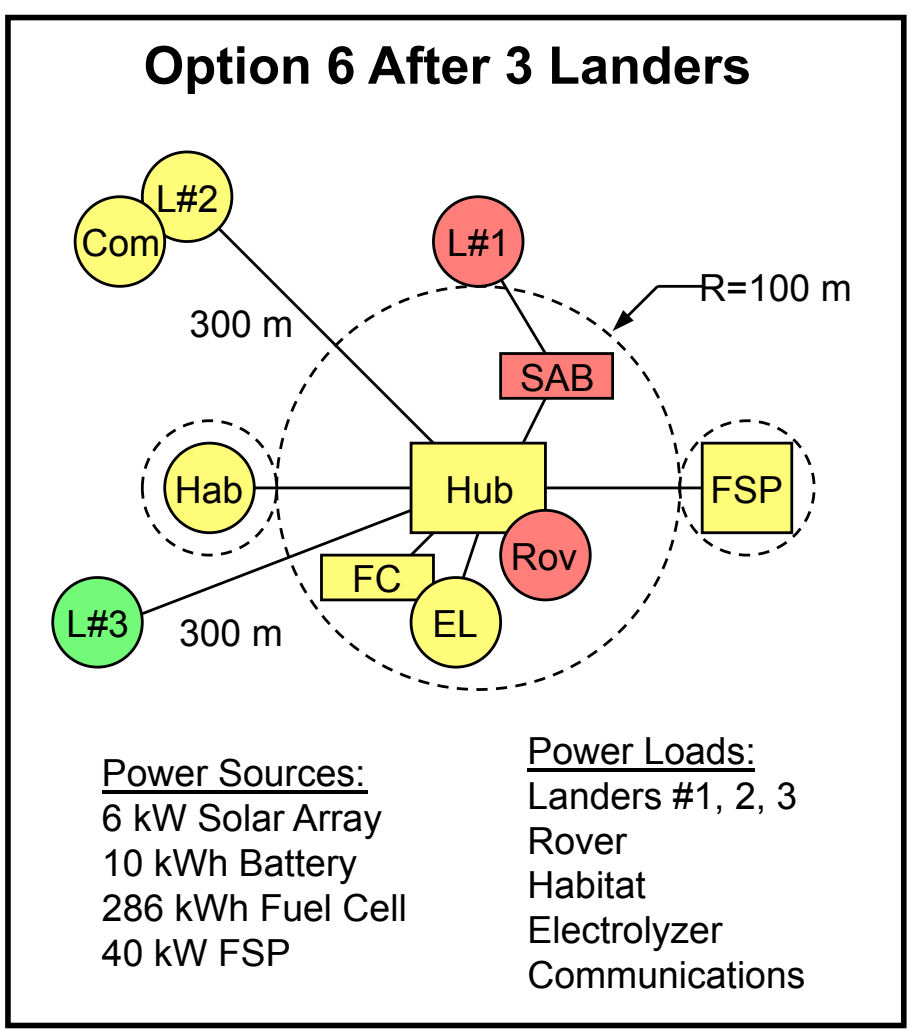

- Compared to PV/RFC-based Architecture for "Solar-Friendly" Lunar South Pole Mission, Option 6 Provides:

- $28 \%$ more day power \& $100 \%$ more night power

- $54 \%$ less total power system delivered mass

- $30 \%$ less total power system cost (development + recurring) 


\section{FSP Site Preparation \& Deployment}

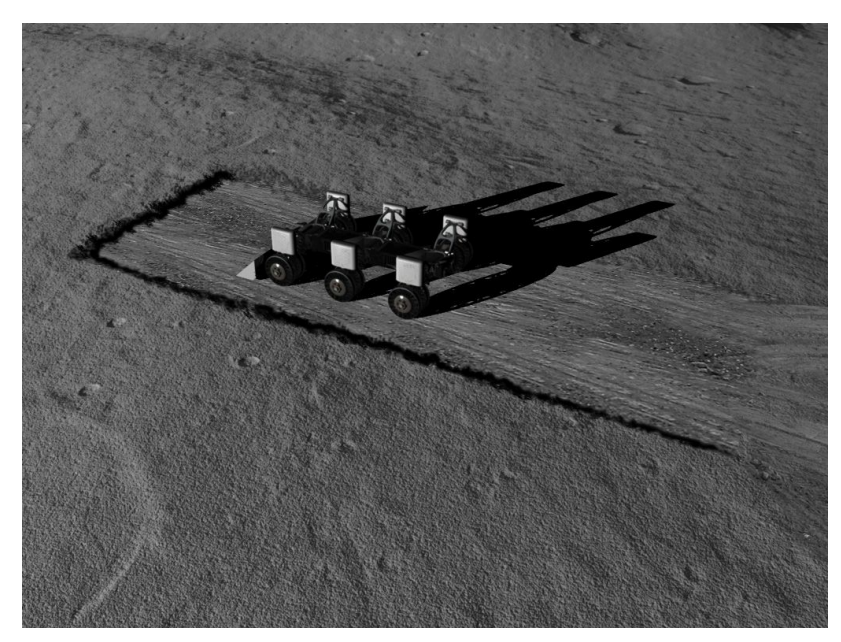

1. Site Selection

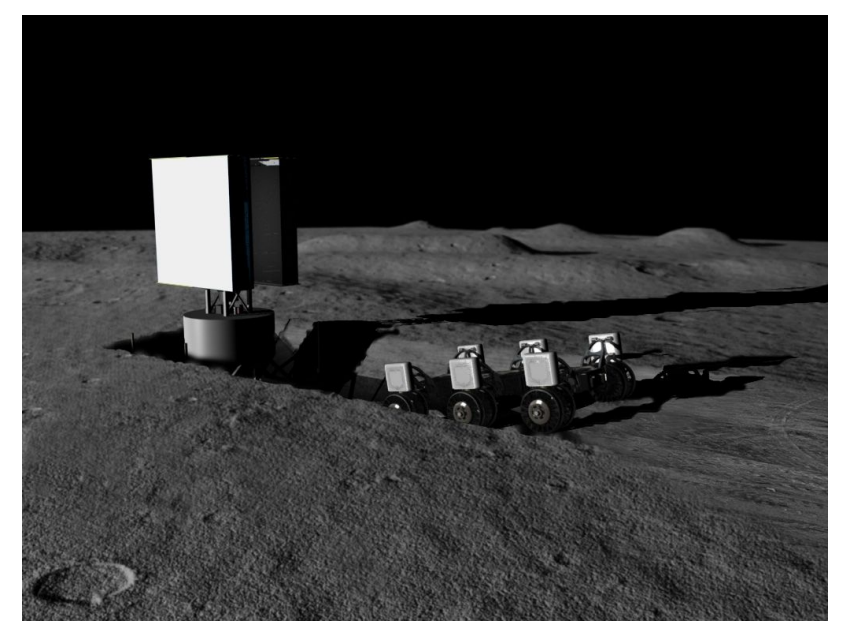

4. Emplacement

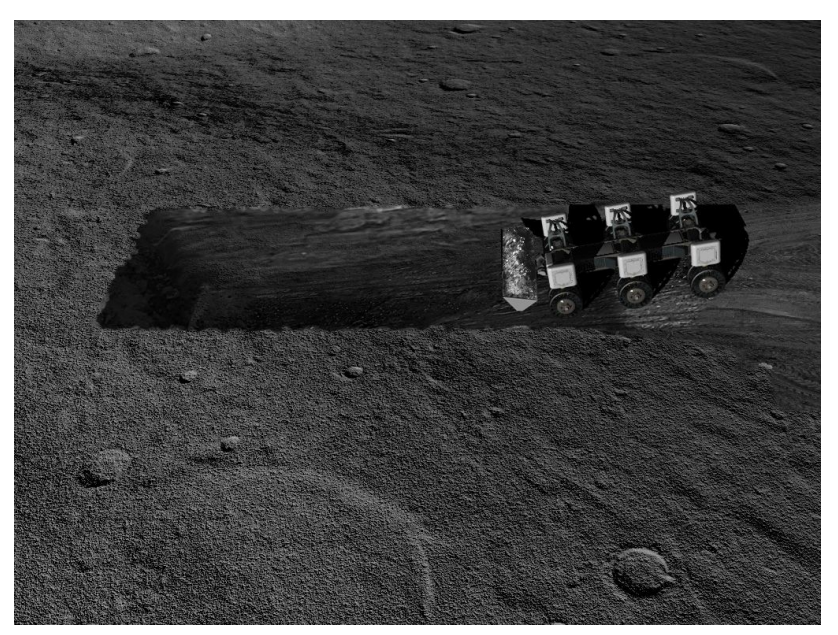

2. Excavation

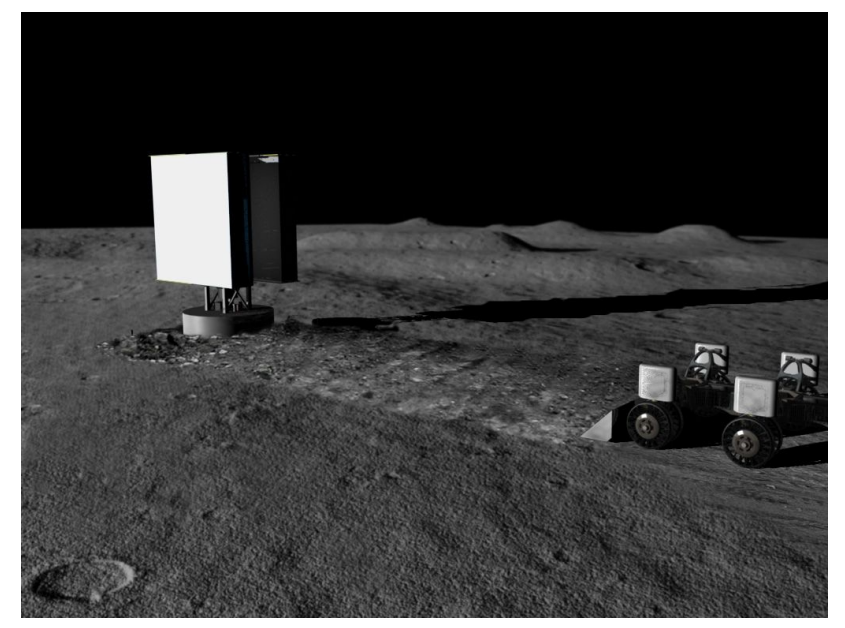

5. Back-filling

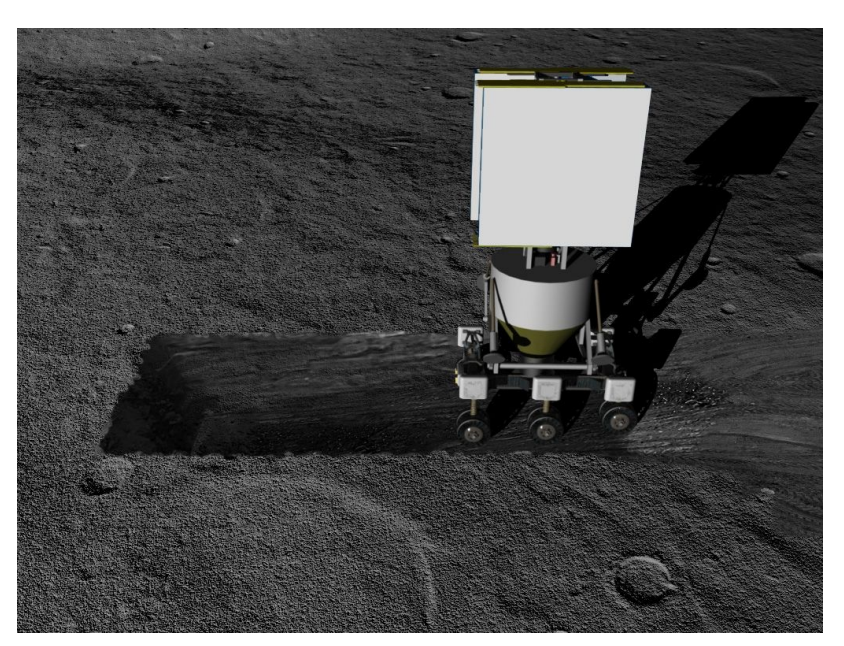

3. Delivery

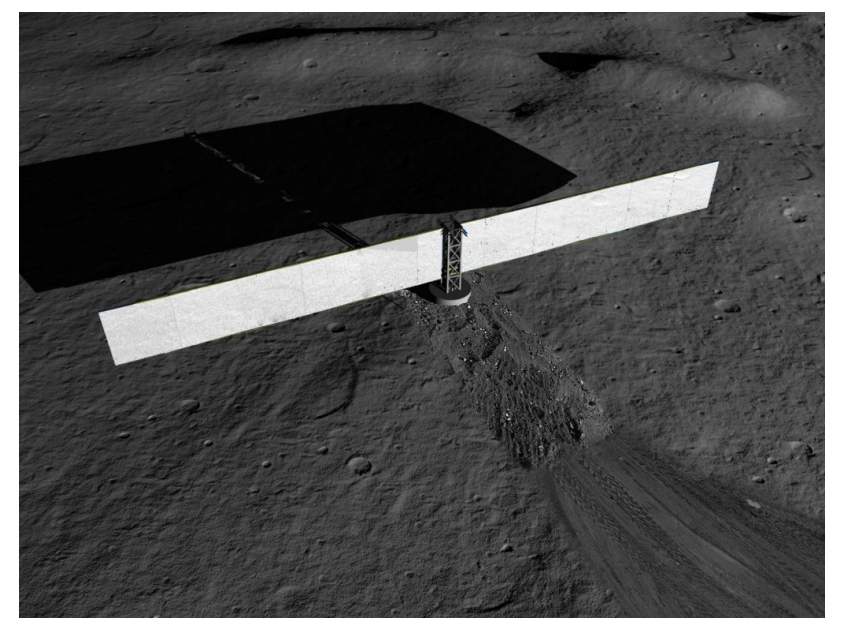

6. Startup 


\section{Mars Design Reference Architecture 5.0}
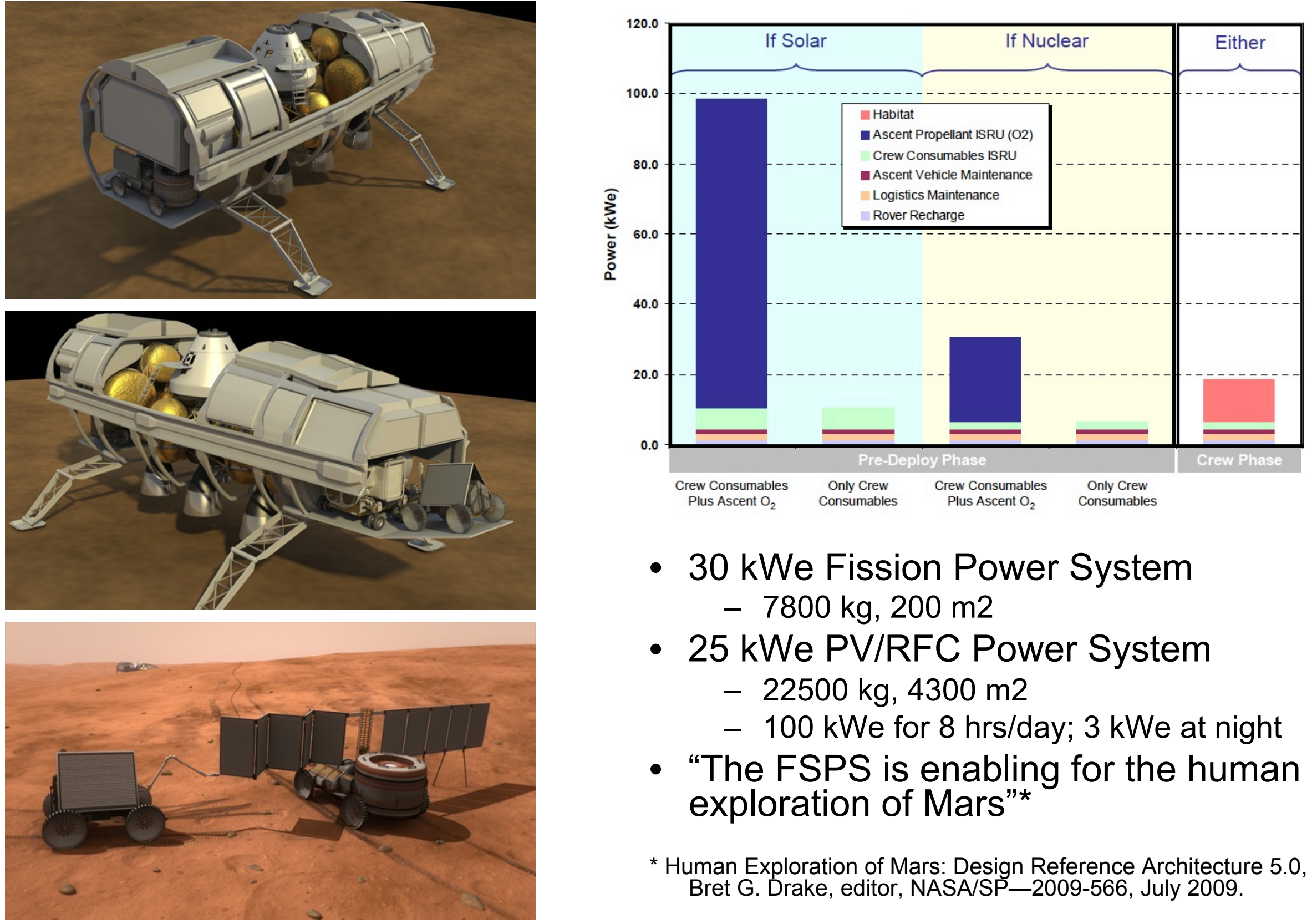

- 30 kWe Fission Power System

- $7800 \mathrm{~kg}, 200 \mathrm{~m} 2$

- 25 kWe PV/RFC Power System

- $22500 \mathrm{~kg}, 4300 \mathrm{~m} 2$

- $100 \mathrm{kWe}$ for $8 \mathrm{hrs} / \mathrm{day} ; 3 \mathrm{kWe}$ at night

- "The FSPS is enabling for the human exploration of Mars"*

* Human Exploration of Mars: Design Reference Architecture 5.0, Bret G. Drake, editor, NASA/SP_-2009-566, July 2009. 


\section{Lunar Surface Systems - Scenario 5}

- Two FSP options selected for LSS Scenario 5

1) FSPS off-loaded and buried

2) FSPS remains on lander

- Common features to both options:

- FSPS delivered on 1st cargo lander

- Central power distribution node at outpost with backup solar array and battery

- On-board shielding is augmented with regolith for reactor radiation dose of $<3 \mathrm{mrem} / \mathrm{hr}$ at specified distance

- Off-Loaded and Buried (5.0.2)

- Lowest mass FSPS ( $5800 \mathrm{~kg})$

- Reactor can be located close to outpost (100 m)

- ATHLETE digs 2 m hole; moves FSPS to site; places FSPS in hole

- Remains on Lander (5.1)

- Greater separation (400 m) to meet radiation dose

- Additional on-board shielding and power cabling results in greater system mass $(\sim 6600 \mathrm{~kg})$

- Requires regolith fill in lander cavity surrounding core

- Bladed rover collects regolith near lander; crane scoops regolith and fills cavity

5.0.2 Off-Loaded \& Buried

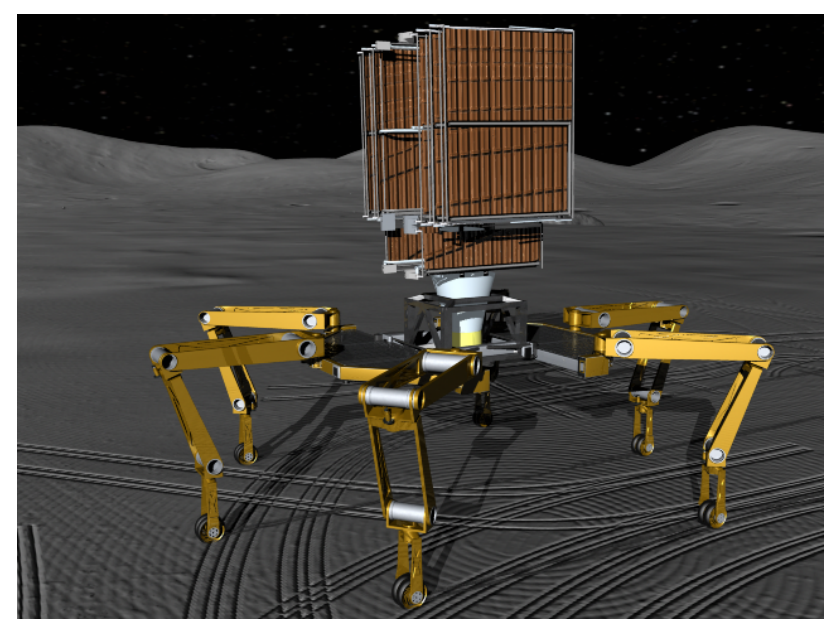

5.1 Remains on Lander

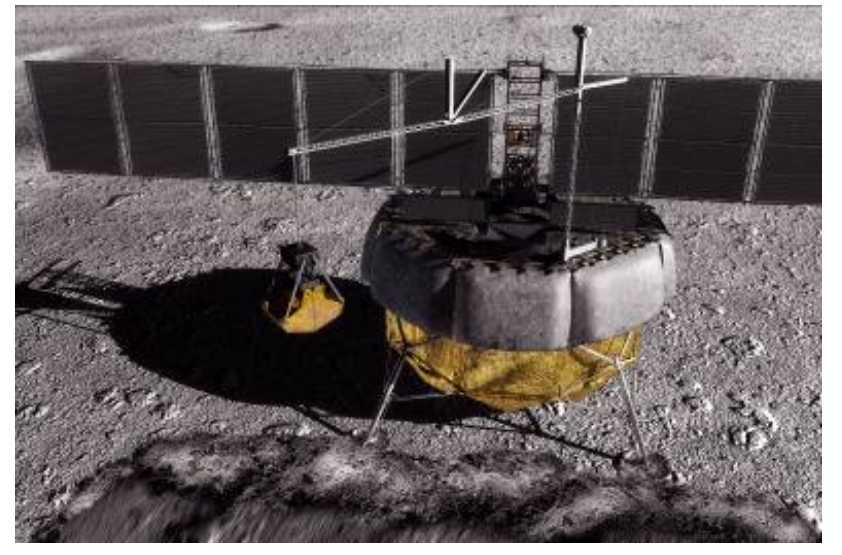




\section{Scenario 5 Shielding Options}

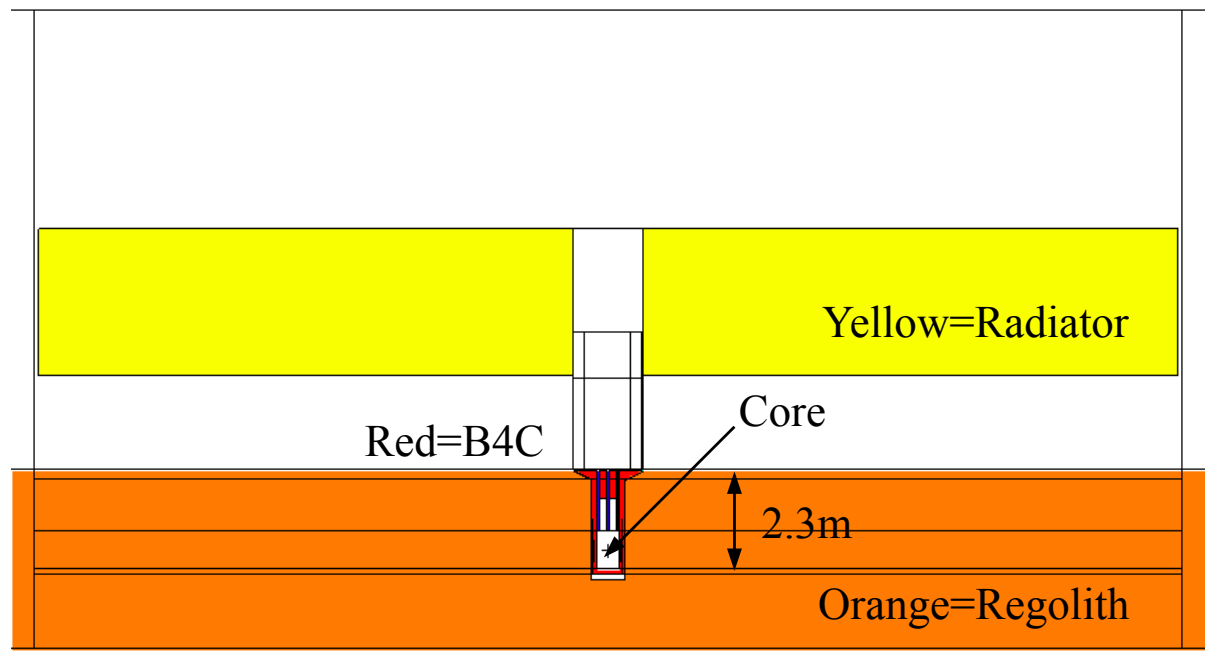

A) FSPS Off-Loaded and Reactor Buried

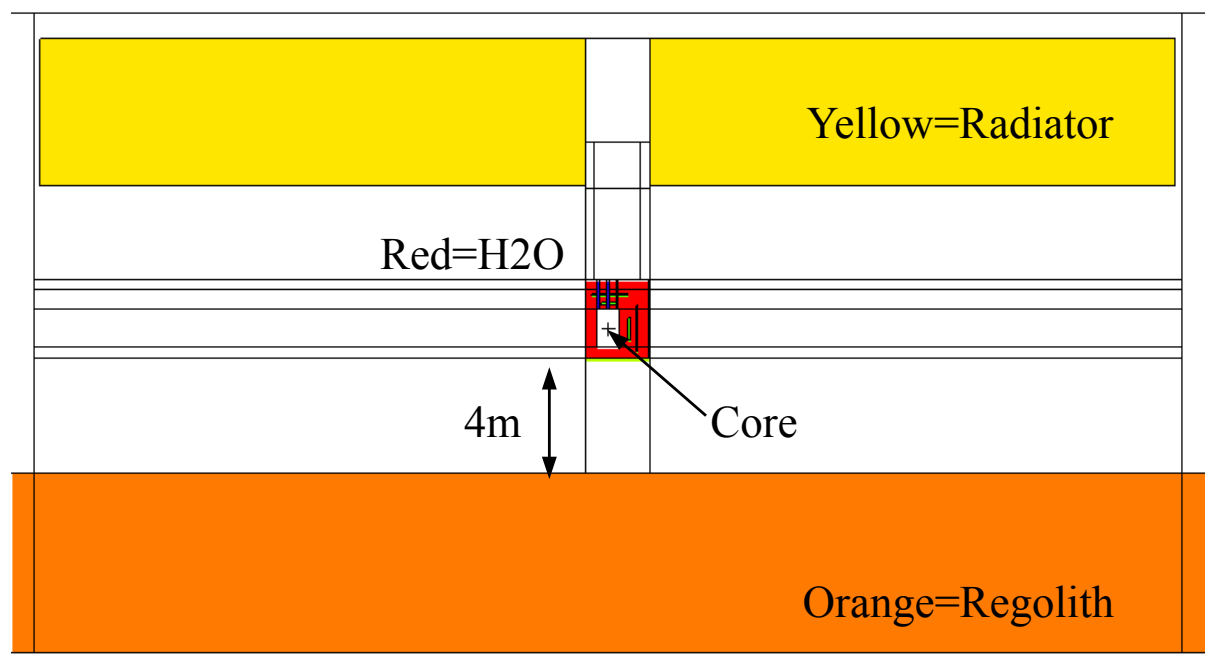

C) FSPS Stays on Lander as Delivered

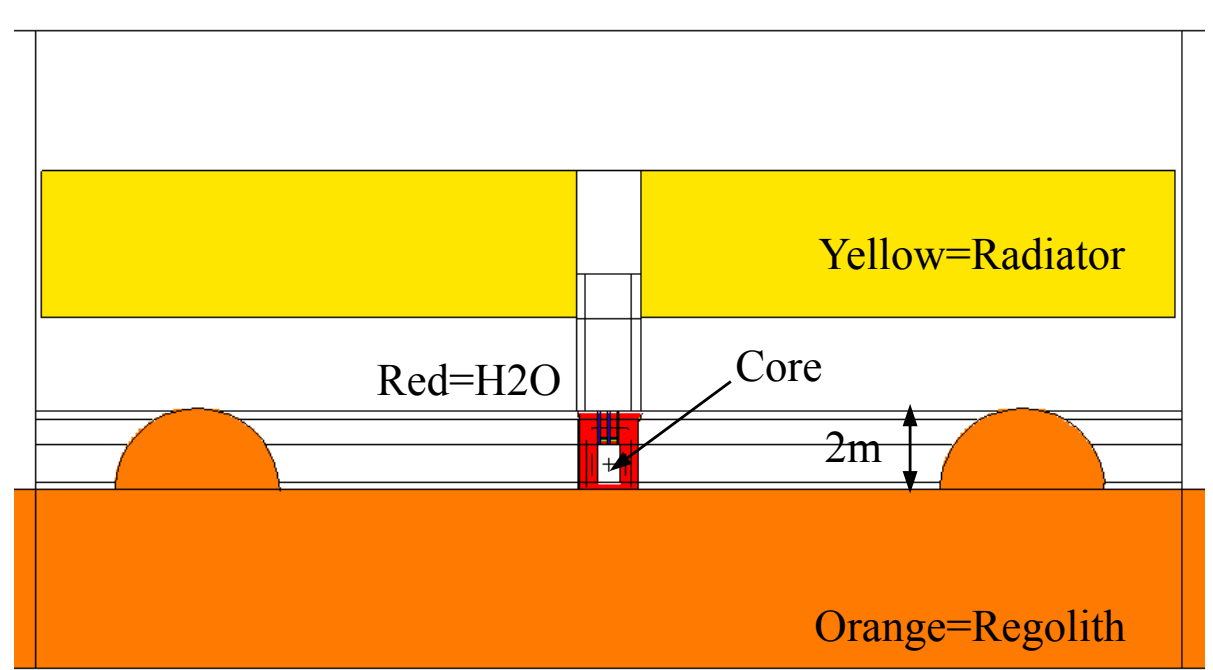

B) FSPS Off-Loaded and Placed in Berm

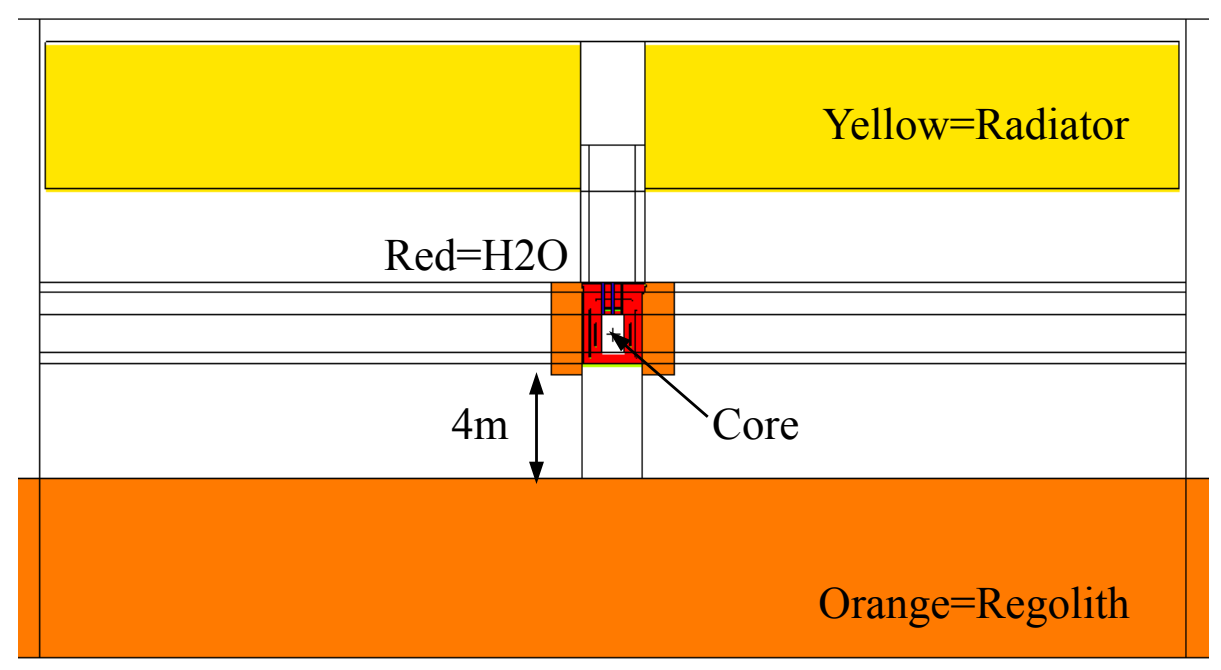

D) FSPS Stays on Lander with Regolith Augmentation 


\section{Lander-Integrated FSP}
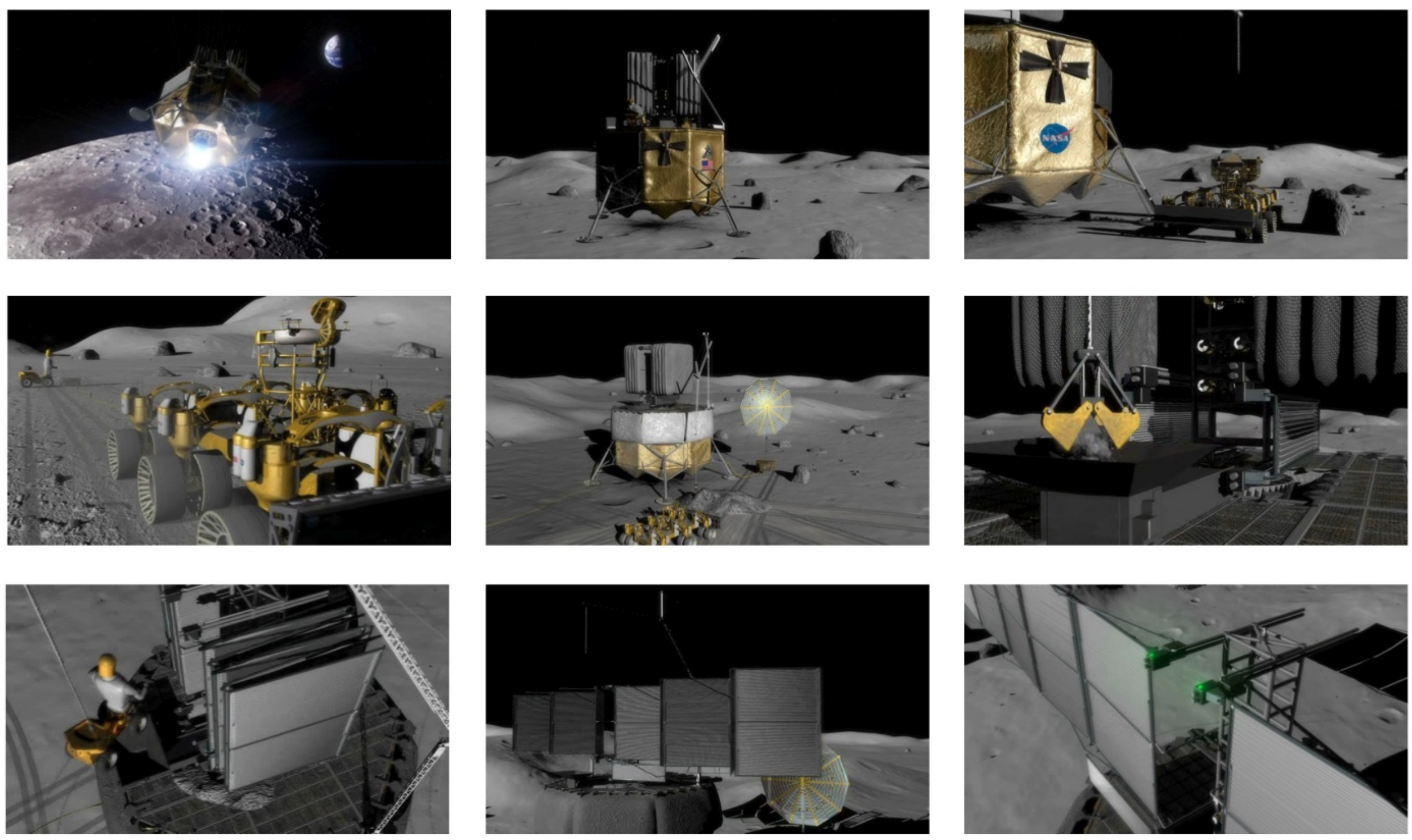


\section{International Global Point of Departure}

- Human lunar architectures evaluated through International Space Exploration Coordination Group (ISECG) with NASA, CNES, DLR, ESA, JAXA, UK, etc.

- Power Function Team formed in April 2009 to define power system options and implementation approaches

- GPoD assumes initial human mission to Shackleton Crater followed by robotic relocation of surface assets for subsequent human missions to Malapert Mountain and Schrodinger Basin

- Mobile architecture favored to maximize science return and utilization of assets

- Afterwards, a single site may be selected for a long-duration mission phase

- Solar-based power systems with regenerative fuel cells are baselined

- However, nighttime power requirements may exceed available energy storage capacity for non-polar relocation missions

- Two nuclear-based options were analyzed including a $2 \mathrm{kWe}$ LargeScale Stirling Radioisotope Generator (LSRG) and a $10 \mathrm{kWe}$ Mobile Fission Power System (M-FPS)

- The MFPS enables both 11-day eclipses at Malapert and 15-day eclipses at Schrodinger

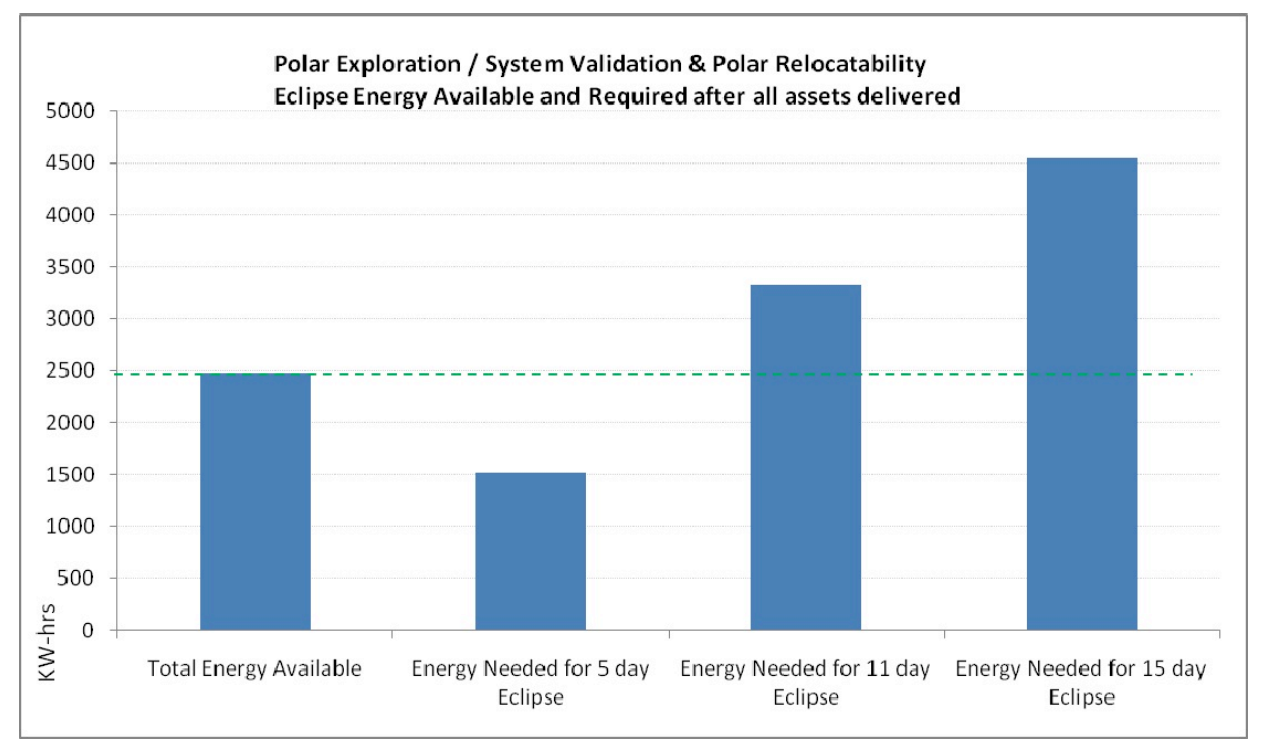




\section{Movable Fission Power System}

- Deliver $10 \mathrm{~kW}$ movable fission system on Malapert cargo lander

- 2000 kg dry mass includes reactor, water shield vessel, power conversion, radiator, power cabling and bus

- $1300 \mathrm{~kg}$ water to be added to shield vessel prior to system startup

- Water could be delivered separately or scavenged from fuel cells

- System would be off-loaded, placed on surface, and surrounded with berm

- Reactor located $\sim 200 \mathrm{~m}$ from crew hab

- Cabling connects reactor to 120 Vdc power bus at crew habitation area

- Shield vessel filled with water and system started in approx. $24 \mathrm{hrs}$

- System can be operated for any duration, shut-down, and relocated

- Post-operation radiation levels would be very manageable

- Water could be drained or left in shield vessel for movement

- Setup would be repeated at new location

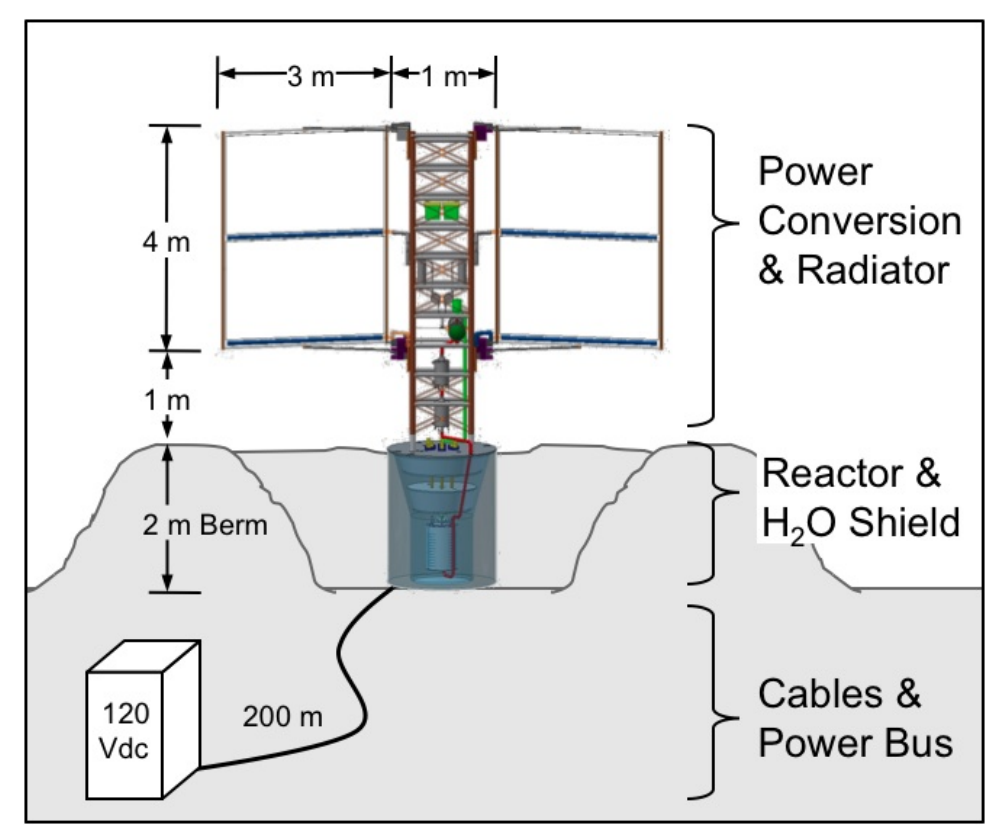

Movable system provides an excellent demo for future higher power unit 


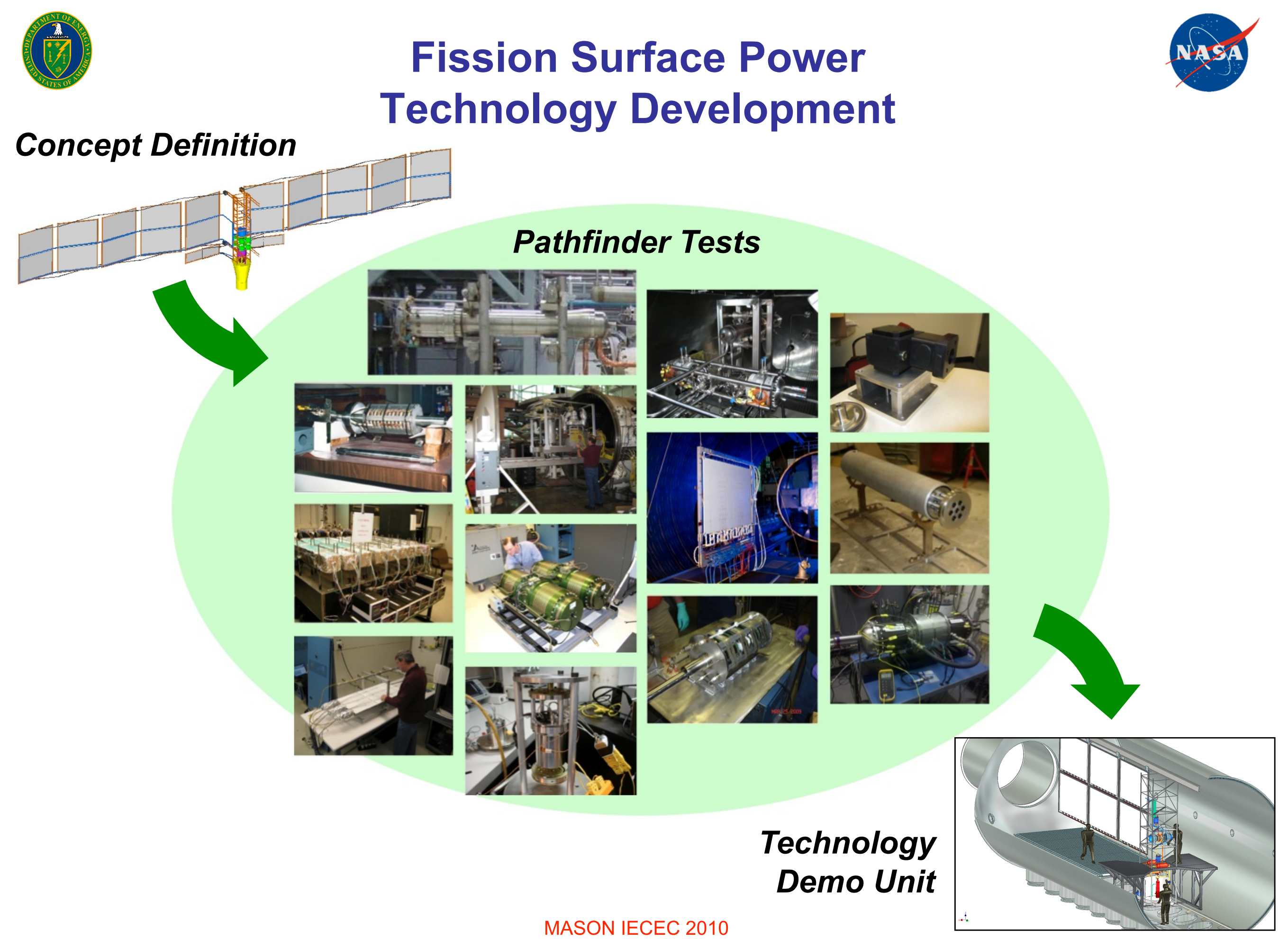




\section{Summary}

- The FSP project has defined a $40 \mathrm{kWe}$ FSP Reference Concept

- Design is based on affordability and low risk

- The benefits of FSP to human exploration include robustness, flexibility, and mission performance

- Various NASA Architecture Studies have evaluated FSP

- Lunar Architecture Team

- Mars Architecture Team

- Lunar Surface Systems/Constellation Architecture Team

- International Architecture Working Group/Power Function Team

- The studies have resulted in multiple FSP configurations and integration approaches

- Buried reactor system

- Cart-deployed system

- Lander-integrated system

- Low power, movable system

- All configurations utilize the same set of FSP component technologies

- The FSP project is poised to demonstrate system-level technology readiness to support a wide range of future NASA missions 